\title{
A FORMAÇÃO DO PROFESSOR NA SALA DE AULA: ATITUDE FRENTE À PESSOA COM DEFICIÊNCIA
}

\section{TRAINING OF THE TEACHER IN THE CLASSROOM: ATTITUDE TO THE PERSON WITH DEFICIENCY}

\author{
DOI: http://dx.doi.org/10.5965/1984317815042019230 \\ Josiane Bertoldo Piovesan \\ Universidade Federal de Santa Maria \\ josiane_piovesan@hotmail.com \\ Francisco Nilton Gomes de Oliveira \\ Universidade Federal de Santa Maria \\ niltonoliveira@superig.com.br \\ Vantoir Roberto Brancher \\ Universidade Federal de Santa Maria \\ vantoir.brancher@iffaroupilha.edu.br \\ Suzel Lima da Silva \\ Universidade Federal de Santa Maria \\ suzellima2@gmail.com
}

\begin{abstract}
RESUMO
Conforme a Lei de Diretrizes e Bases da Educação (LDB), $n^{\circ} 9.394 / 1996$, as políticas educacionais atuais vislumbram a inclusão de crianças com deficiências múltiplas no ensino regular. O processo administrativo e acadêmico da escola, a partir da Lei, teve que se adaptar para atender às singularidades e pluralidades humanas dessas pessoas, rompendo o paradigma do modelo tradicional para um modelo mais inclusivo. Outra adaptação recai no professor, ao lidar com esse contexto situacional da pessoa com deficiência em sala de aula. Desafios esperam os docentes, uma vez que pesquisas apontam para o possível despreparo destes profissionais para lidarem com o público alvo da Educação Especial. Neste sentido, este artigo trata-se de uma revisão sistemática, que aborda a temática da formação docente para a educação inclusiva em ensino regular. A metodologia foi realizada a partir da busca nas plataformas do Portal CAPES e do Portal Scielo, em busca de artigos científicos que estivessem de acordo com a temática, a partir da relevância do tema. Essa pesquisa possibilitará uma discussão sobre os artigos encontrados em relação à temática investigada, bem como uma reflexão sobre o que os autores têm discutido sobre o assunto, visando atualizar os leitores sobre o tema. O estudo permitiu uma reflexão sobre a atual conjuntura que a educação inclusiva repercute no sistema educacional brasileiro, bem como no cotidiano do professor em sala de aula. Neste mote, esta pesquisa servirá de suporte reflexivo aos leitores/pesquisadores que se interessem por esta temática.
\end{abstract}

Palavras-chave: Formação de Professores. Formação Docente. Educação Inclusiva. Ensino Regular.

\section{ABSTRACT}

According to the Education Guidelines and Bases Law (EGBL) n 9.394 / 1996 current educational policies envisage the inclusion of children with multiple disabilities in regular education. The administrative and academic process of the school from the Law had to adapt to meet the singularities and human pluralities of these people, breaking the paradigm of the traditional model to a more inclusive one. Another adaptation rests with the teacher in dealing with this situational context of the person with disabilities in the classroom. Challenges await 
teachers as research points to their potential unpreparedness to deal with the target audience of Special Education. In this sense, this article is a systematic review, which addresses the theme of teacher education for inclusive education in regular education. The methodology was based on the search of the CAPES Portal and the Scielo Portal, in search of scientific articles that were in accordance with the theme, based on the relevance of the theme. This research will enable a discussion about the articles found in relation to the subject investigated, as well as a reflection on what the authors have discussed on the subject, aiming to update the readers on the subject. The study allowed us to reflect on the current conjuncture that inclusive education has repercussions on the Brazilian educational system as well as on the daily life of the teacher in the classroom. In this motto, this research will serve as a reflective support to the readers / researchers who are interested in this topic.

Keywords: Teacher Training. Teacher Training. Inclusive education. Regular education.

\section{INTRODUÇÃO}

Conforme o Decreto $\mathrm{n}^{0} 7.611 / 2011$, a política inclusiva no Brasil, a partir de uma disseminação, convida a escola a discutir e rever suas concepções e práticas. Visando às diferenças e à ruptura com um sistema educacional segregador, desenvolve projetos e uma demanda de exigências que recai no docente, um trabalho com turmas cada vez mais heterogêneas, atendendo a alunos das mais diversas realidades sociais e com as mais variadas necessidades específicas. Tem-se observado que o sistema educacional ainda se organiza de forma bastante segregadora. Utiliza-se este termo corroborando a ideia proposta por Sassaki (2005, p. 21), que discorre em seu estudo exemplos observados no sistema educacional brasileiro, que permanece segregando as pessoas com necessidades educacionais especiais a exemplos de atitudes, tais como: uso de uma escola especial junto à comunidade; classe especial numa escola comum; setor separado dentro de uma empresa; etc. Assim, conclui-se que o cumprimento dos direitos das pessoas com deficiência ainda é insatisfatório, uma vez que a integração pouco exige da sociedade no que tange a mudanças de comportamento, da criação de espaços adequados, objetos adaptados e de práticas sociais. Ou seja, faz-se necessário ultrapassar o paradigma excludente e o paradigma integracionista, e migrar, de fato, para uma sociedade inclusiva, na qual o respeito e a valorização das diferenças sejam, de fato, a regra, e não a exceção. 
Sendo assim, as discussões e debates acerca da temática têm sido cada vez mais recorrentes. Contudo, a partir das modificações do processo de transformação no trabalho docente, os professores apresentam um sentimento de desconfiança sobre a qualidade de sua formação, o que traz insegurança e dúvidas acerca da execução do projeto inclusivo nas escolas (DUEK, 2014). A partir destes debates e dúvidas, presentes na sociedade bem como o desconforto apresentado pelos professores, faz-se mister novas reflexões que apontem caminhos a serem seguidos pelos educadores. Busca-se descobrir quais caminhos e atitudes dos docentes podem fazer a diferença no que tange à qualificação do ensino a todos, sem segregação dos alunos, para a além da educação básica.

Por meio de uma retomada histórica, as ideias sobre inclusão foram introduzidas pela Constituição da República Federativa do Brasil. Com a promulgação da Lei de Diretrizes e Bases da Educação Nacional (LBDEN), Lei nº 9.349/1996, foram efetivadas concretamente as políticas de inclusão na educação escolar. $O$ atendimento às pessoas com necessidades educacionais especiais trata-se de uma modalidade de educação escolar que considera todos os níveis, da educação básica à educação superior, e também a educação de jovens e adultos e a educação profissional (ARAÚJO et al., 2010).

A formação de professores pode influenciar qualitativamente para a efetivação das políticas inclusivas e o estabelecimento da inclusão escolar (SOUZA PRAIS et al., 2017). O professor é o elemento chave para o sucesso dos progressos de mudança, o que agrega grande preocupação com a formação desses profissionais (ARAÚJO et al., 2010). Esse aspecto tem sido objeto de estudo (GLAT, PLETSCH, 2010; VITALIANO, 2010; SOARES, 2010), salientando a imediata necessidade de uma mudança na formação pedagógica dos professores, analisada de modo que contribua para um ensino com maior compromisso ético e político, considerando as exigências impostas pelo atual contexto (PRAIS e DA ROSA, 2017).

Neste condão, este artigo trata-se de uma revisão sistemática, que aborda a temática da formação docente para a educação inclusiva em ensino regular. Metodologicamente, foi realizada uma investigação nas plataformas do Portal 
CAPES e Scielo, em busca de artigos científicos que estivessem de acordo com a pesquisa, a partir da relevância do tema.

Neste sentido, este estudo possibilitará uma discussão sobre os artigos encontrados em relação à matéria investigada, bem como uma reflexão sobre o que os autores têm discutido sobre o assunto nas conclusões dos trabalhos, visando atualizar os leitores sobre esse estudo.

\section{BALIZADORES TEÓRICOS}

A inclusão é uma questão de direitos, mas é, também, uma questão de atitude, que implica em mudanças na organização e na prática pedagógica da escola. Tais mudanças agregam dificuldades às atividades docentes, uma vez que tais profissionais se deparam com a necessidade de encontrar respostas para a turma, considerada heterogênea. Nesse contexto, é fato notório que os alunos têm direito de participar e aprender, independentemente de suas necessidades educacionais (SILVA, 2013).

Com a promulgação da Lei 9.394/96, que estabelece as Diretrizes e Bases da Educação Nacional no Brasil, o acesso à educação de pessoas com necessidades educacionais especiais está explicitado no artigo 58 da Constituição Federal de 1988 que a Educação Especial é "uma modalidade de educação escolar oferecida a educandos com necessidades especiais, preconizando o seu oferecimento, na rede regular de ensino" (BRASIL, 1996, p. 19). Nesse sentido, Regiani e Mól (2013, p. 124) referem que para haver mudanças no comportamento segregacionista da sociedade, há a necessidade de flexibilização e adaptação do sistema educativo para que, então, as reflexões sobre as políticas educacionais possam iniciar um processo de mudança. Outra mudança relevante é referente ao papel de facilitador do professor, ao lidar com alunos com necessidades educacionais especiais em sala de aula, considerando-se que, pedagogicamente, ele não foi capacitado para lidar com esse cenário. Esta é uma realidade apontada pelas pesquisas e pelos estudos aqui analisados. 
A formação de professores, a convivência com a diversidade e a relação família-escola são alguns dos principais desafios enfrentados pelos atores educacionais no cotidiano escolar, mediante a necessidade de escolarizar alunos com $\mathrm{Ne}$ cessidades Educativas Especiais (NEEs) (MATOS; MENDES, 2015). Pessoas com NEEs são as que apresentam impedimentos de longo prazo, de natureza física, mental e intelectual ou sensorial, os quais restringem sua participação efetiva na escola ou na sociedade (FERNANDES, T. L. G.; VIANA, T. V., 2009).

Magalhães (2003) ainda especifica este público como: alunos com dificuldades de aprendizagem, problemas de comportamento, deficiência física sensorial (cegos, surdos e surdos-cegos), deficiência física não-sensorial (paralisia cerebral, por exemplo), deficiência mental, deficiências múltiplas. Somam-se a este grupo os alunos com altas habilidades (superdotação) que necessitam de currículo diferenciado, devido à sua superior capacidade diferenciada de aprendizagem. As escolas ainda se encontram distantes do que preconizam os documentos oficiais sobre inclusão, e são espaços contraditórios, que pregam práticas de discriminação e conscientização (MATOS; MENDES, 2015).

Quanto às dificuldades ainda observáveis, de acordo com Lopes (2010, p.58), tem-se que,

[...] a insuficiência de recursos especializados, o elevado número de alunos em sala de aula, a insuficiência de tempo para dar atenção àqueles que têm mais dificuldades, os diferentes ritmos de aprendizagem, a dificuldade que os professores têm de "descolar" dos conteúdos das disciplinas que leccionam, em paralelo com a falta de motivação dos alunos e com a percepção de que as dificuldades se agravam se o aluno estiver numa turma onde haja muita indisciplina.

A formação de professores é um contributo importante para refletir sobre as vastas questões que disseminam esta concepção de escola. Não menos importante, é necessário ter confiança para implementar respostas diferenciadas, é saber-fazer, considerando a heterogeneidade da turma, em que não faz sentido que as diferenças impliquem em atividades distintas para alguns (SILVA, 2013).

As temáticas de inclusão escolar precisam ser incorporadas à formação dos professores, coadunando um processo de reflexão e, concomitantemente, com rup- 
turas de paradigmas da atuação do professor em sala de aula. Os cursos de Licenciatura precisam ter mais disciplinas transversais e práticas que discutam e capacitem estes professores/futuros professores a lidar com alunos com necessidades educacionais especiais. Não esquecendo que as licenciaturas também têm que se adaptar às suas matrizes curriculares, para atender ao que preconiza a política nacional de educação inclusiva.

A partir disso, o objetivo deste estudo foi traçar as atuais discussões sobre esse tema, considerando as conclusões encontradas nos materiais pesquisados, acerca da formação docente no tocante à educação inclusiva.

\section{METODOLOGIA}

Este artigo trata-se de uma revisão sistemática, que abordou a temática da formação docente para a educação inclusiva no ensino regular, realizada em três etapas: busca por descritores no Portal CAPES e Scielo, seleção dos artigos, a partir da leitura dos resumos coerentes com o tema da pesquisa e, por fim, fichamento dos artigos. Para delineamento da pesquisa, fez-se, inicialmente, uma busca por associação com os descritores, a qual evidenciou uma relação demasiadamente vasta para a proposta investigada, totalizando cerca de 100 artigos.

A escolha pela revisão sistemática se deu devido ao fato de tratar-se de uma investigação com critérios definidos, que visa identificar, selecionar, avaliar e sintetizar as evidências relevantes disponíveis. De acordo com Galvão e Pereira (2014, p. 183), a grande contribuição desse tipo de pesquisa se dá pela divulgação dos critérios adotados, com os quais se permite que outros pesquisadores possam repetir o procedimento, sendo, desse modo, considerada uma boa estratégia para tomada de decisão à continuidade da pesquisa.

Em vista do número considerável de publicações, houve a necessidade de realizar uma nova busca, pensando em critérios de inclusão, tais como: publicações dos últimos cinco anos (2013-2018), descrição em português, disponibilidade do texto, na íntegra, e necessidade de associações dos descritores: formação de profes- 
sores e educação inclusiva; ensino regular e educação inclusiva; formação docente e ensino regular; formação de professores e ensino regular. Levando em conta os critérios disponíveis nos portais, foram utilizadas como filtro de escolha a primeira palavra-chave de cada associação presente no título dos artigos e a segunda palavra integrante no decorrer do texto, ou seja, resumo e texto completo.

$\mathrm{Na}$ segunda etapa, foi realizada uma seleção dos resumos, como uma forma de filtrar os trabalhos, visto que o número ainda era considerável. Optou-se pelas leituras dos resumos de cada trabalho, para verificar se este número seria diminuído. Neste exercício da leitura, no qual foram priorizados aqueles textos que apresentavam claramente intervenções de educação inclusiva no ensino regular, englobando a formação dos professores para a prática inclusiva, resultando em 75 artigos científicos a serem analisados e discutidos.

Posteriormente, os artigos selecionados foram lidos na íntegra e fichados, de acordo com o interesse deste estudo. Na sequência, os dados foram organizados em gráficos para uma melhor visualização das informações coletadas.

\section{RESULTADOS E DISCUSSÕES}

A partir da pesquisa, foram encontrados ao todo, no Portal CAPES, levando em conta as associações das palavras-chave (formação de professores e educação inclusiva; ensino regular e educação inclusiva; formação docente e ensino regular; formação de professores e ensino regular), respectivamente, 17, 9, 1 e 13 artigos. O número de publicações resultantes da primeira busca se deu somente pela leitura dos títulos, excluindo aqueles encontrados em duplicidade.

Considerando a leitura dos resumos, o número de trabalhos selecionados resultou, respectivamente, em 12 (formação de professores e ensino inclusiva), 5 (ensino regular e educação inclusiva), 1 (formação docente e ensino regular) e 2 (formação de professores e ensino regular). O número significativo de exclusões para a associação (formação de professores e ensino regular) se deu devido ao fato dos artigos não terem relação frente à formação de professores e relação com o contexto da educação inclusiva. As publicações analisadas no Portal Capes resultou em 
um total de 20 artigos. No que se refere à busca no Portal Scielo, utilizando as mesmas associações de palavras-chave, foram encontrados, respectivamente, 33, 16, 7 e 15 artigos. Esse montante se deu seguindo a mesma metodologia do Portal Capes, iniciando pela leitura dos títulos que continham, pelo menos, uma das palavras-chave no trabalho publicado. A partir da leitura dos artigos, foram excluídos deste estudo, 5 trabalhos em desacordo com o tema e 11 artigos em duplicidade, permanecendo um total de 55 artigos para a discussão.

Vislumbra-se, a partir da busca no Portal Capes e Scielo, utilizados nesta pesquisa, banco de dados qualificados para atualizar a discussão sobre a temática deste estudo, uma vez que o número de publicações pôde traçar as principais questões abordadas. Apresentando conclusões pertinentes sobre a necessidade de qualificação do professor, frente ao processo de inclusão escolar, com considerações pertinentes acerca das atitudes dos docentes em relação ao aluno com deficiência na escola regular.

No Gráfico 1, destaca-se a significância dos materiais utilizados para fichamento, revelando que a base de dados Scielo apresenta o maior número de publicações para a associação entre: Formação de Professores e Educação Inclusiva (29 artigos); Educação Inclusiva e Ensino Regular (16 artigos) e Formação Docente e Ensino Regular (3 artigos). Já no portal da CAPES, o número mais significativo de publicações se deu pela associação das palavras-chave, Formação de Professores e Ensino Regular (12 artigos). 
Gráfico 1. Amostra de publicações encontradas para cada combinação de palavras-chave.

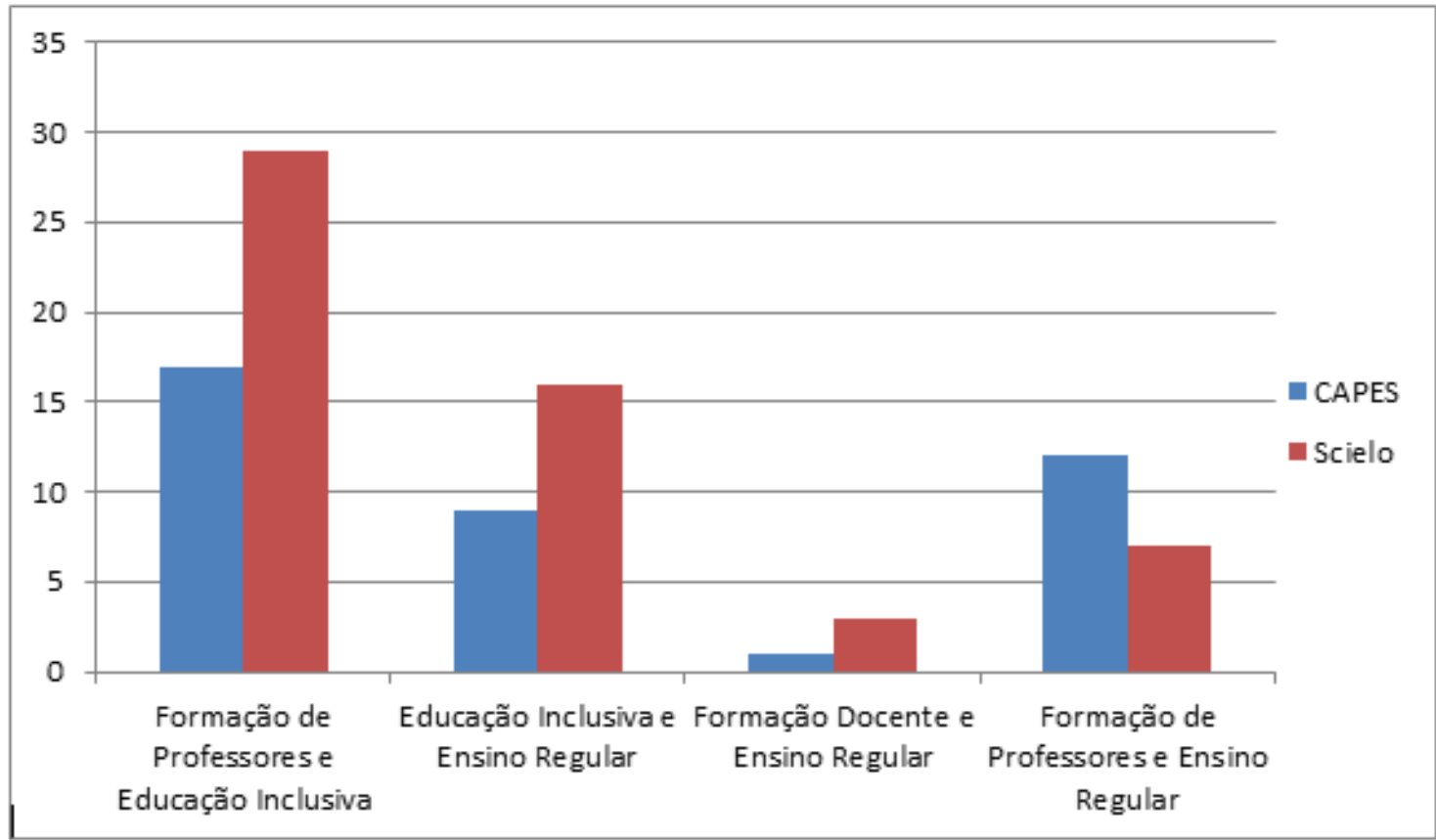

Fonte: Elaborado pelos autores (2018).

O montante final a ser discutido soma 75 artigos científicos em revistas da área da Educação, que contemplam ações da formação de professores.

As duas bases de dados pertencentes a esta pesquisa (Portal CAPES e Scielo) foram consideradas suficientes, considerando que conseguem fazer esse panorama da temática formação docente e ensino regular, qualificando as informações apresentadas. Ambas as bases de dados sinalizaram que há formação para os professores lidarem com a inclusão escolar no ensino regular.

Para melhor apresentação do material encontrado, dividiu-se em categorias, conforme associação das palavras-chave: formação de professores e ensino regular, formação de professores e educação inclusiva; educação inclusiva e ensino regular, e formação docente e ensino regular. 


\section{FORMAÇÃO DE PROFESSORES E ENSINO REGULAR}

Considerando o caráter emergencial da atual política de inclusão escolar no Brasil, os professores das classes comuns se veem desprovidos de preparo específico para atender a esta população e, com isso, torna-se imperativo buscar estratégias que possam contribuir com este processo, concomitantemente à educação inclusiva.

Uma das questões que acometem a falta de preparo dos professores e a insegurança refere-se à ausência de apoio da escola. As carreiras transformam-se em batalhas, em que cada um precisa enfrentar os processos da sua autoformação. Em alguns casos, ocorrem práticas ineficazes, e os vícios profissionais que prejudicam a construção de uma ação eficiente (ZABALZA, 2004).

No que tange à formação de professores, a pesquisa de Machado e Costas (2013) traz um panorama sobre a necessidade de se continuar a aprofundar as questões sobre a formação de tais profissionais para a educação inclusiva. A formação do professor é um processo que engloba vários aspectos, devendo ser entendida como: "um processo amplo que engloba tanto desenvolvimento pessoal quanto profissional dos professores envolvidos" (BRANCHER, 2013, p. 71). Por isso a importância de, reiteradamente, se discutir, refletir e aprofundar estudos sobre a formação docente.

Mais uma vez, se discute a importância de dar uma atenção especial à formação inicial e continuada do professor, como importantes elementos à constituição deste profissional. É imprescindível discutir uma forma de pensar para além da política da educação inclusiva, entendendo que a permanência no nível da legislação existente não pressupõe a construção de um fazer com práticas que, definitivamente, incluam os estudantes com necessidades educacionais especiais.

Partindo do pressuposto que a valoração histórica da educação inclusiva está focada nos Anos Iniciais, essa questão pode refletir negativamente, quando se percebe a inserção desses alunos no Ensino Médio, Técnico e Superior, pois o professor pode não ter recebido formação para atuar com este público específico. Esse aspecto reflete a urgência de mudanças no que tange ao envolvimento, tanto dos 
professores, como da gestão das universidades e demais espaços de formação dos cursos de Licenciaturas, colegiados de cursos e núcleos de docentes estruturantes, para uma gestão mais democrática e com impacto na formação de professores para a inclusão.

Nessa mesma questão, Cabral et al. (2014) discorrem sobre o ensino colaborativo, no qual o professor tradicionalmente individual passa a atuar de forma que possibilite compartilhar mais as metas, decisões, avaliações e demais ações no contexto educativo. Com essas mudanças, vislumbra-se a implantação da Educação Especial na perspectiva do professor da sala de aula regular aproximar-se do professor que trabalha com o aluno especial, ampliando a construção, planejamento, adaptações curriculares e avaliação.

A necessidade de implementação de programas que capacitem o docente para atuar com os alunos que apresentam necessidades educacionais especiais é emergente, uma vez que isso refletirá em melhores resultados das práticas educacionais. A inclusão deve garantir reflexões e ações que garantam o ingresso, a permanência e a formação qualificada dos alunos, os quais precisam concluir os estudos devidamente instrumentalizados para a vida em sociedade. Caso contrário, pode-se dizer que ocorrem práticas pedagógicas excludentes (ASPILICUETA et al., 2013).

\section{FORMAÇÃO DE PROFESSORES E EDUCAÇÃO INCLUSIVA}

As condições históricas a respeito da educação inclusiva criaram circunstâncias nas quais foi dada atenção à escolarização da pessoa com deficiência, a qual deveria se adaptar às exigências da escola. Atualmente, se observa que é a escola que deve se adaptar às necessidades dos alunos, buscando atender com qualidade diversidades existentes (SANTOS e ARAÚJO, 2016).

Essas mudanças em prol de uma educação inclusiva no ensino regular deveriam continuar além da educação básica, como tradicionalmente se vislumbra práticas de formação de professores na educação inclusiva. Mudanças nesse sentido permitiriam que, à medida que o aluno com necessidades educacionais cursasse 
o ensino Ensino Médio, teria garantida a construção de habilidades e competências para avançar em sua profissionalização e, posteriormente, sua inserção no mundo do trabalho. Uma mudança significativa se dá por práticas inclusivas, contempladas em leis, de forma clara, com propósitos bem definidos, sem exclusão, fomentando as discussões a quem se interessar pelo assunto, bem como com profissionais qualificados e preocupados com o desenvolvimento humano.

Cabe registrar que essas mudanças podem estar presentes nas ementas curriculares em todas as fases/modalidades do ensino.

Rodrigues e Lima-Rodrigues (2017) também têm abordado a formação de professores como estratégia capaz de motivar o futuro profissional da educação a se adaptar a novas situações, para que se sintam mais seguros e capazes de lecionar, de forma não discriminatória, e promover os valores da Educação Inclusiva.

Além da falta de conhecimento dos docentes, suas práticas também podem ser comprometidas pela escassez de formação continuada, inexistência do trabalho colaborativo aliada a longas jornadas de trabalho e a má remuneração, entre outros fatores (PLETESCH, ARAÚJO e LIMA, 2017).

Lima-Rodrigues (2017) mostram como exemplo de transformação do professor, frente ao processo de inclusão escolar, a significância dos momentos de partilha e reflexão, oportunizados por momentos bem estruturados, por via de projetos de capacitação para a inclusão escolar. Corrobora isso Silva (2015), quando aborda que a formação de professores, depende da presença de profissionais qualificados nas instituições formadoras, com conhecimentos relacionados às áreas que envolvem o público da educação especial. Os cursos de formação inicial e continuada de professores devem instrumentalizá-los de maneira adequada, uma vez que isso servirá para melhorar a compreensão destes profissionais frente à realidade, para que possam interferir nela de forma crítica, criativa e propositiva.

Nos cursos de formação continuada é bastante frequente que tenham cursos de "suplência ou atualização dos conteúdos" de ensino (PIMENTA, 1999). Porém, eles se mostram ineficientes às práticas escolares e mudanças, por se apresentarem, na maioria das vezes, fora do contexto escolar (PIMENTA, 1999). A in- 
serção no contexto de atuação promove o entendimento de tal ambiente e possibilita a melhoria da prática docente.

Nessa linha de raciocínio, Otalara e Dall'acqua (2016) referem que ambientes menos restritivos e avaliações não discriminatórias são alguns pontos que mereceram atenção, sendo que estas devem permitir o redesendo de políticas de Educação. Logo, percebeu-se que a inclusão escolar é um desafio que se apresenta para o professor da sala de aula regular. Antunes, Rech e Ávila (2016) corroboram que a formação de professores torna-se fundamental para que a inclusão seja uma prática, e não um mero discurso presente nos espaços educacionais e sociais e nas políticas que regem as escolas brasileiras.

Há muito esforço, reflexões e discussões teóricas sobre as políticas de inclusão e formação de professores, porém, poucas produções ainda relatam práticas pedagógicas realmente efetivas sobre o tema. Parece, também, que há pouca alteração nos currículos, bem como inflexibilidade por parte dos gestores e escolas, para que se efetive, na prática, a formação docente para a inclusão escolar.

Tavares, Santos e Freitas (2016) propõem que os currículos abordem a temática da inclusão, não apenas na esfera específica, mas transversalmente a outras disciplinas, nos cursos de formação de professores. Isso propiciará naturalidade ao lidar com as deficiências e também fomentará discussões acerca do tema. Implementar nos cursos de formação de professores interação com pessoas com necessidades educacionais específicas também tornará as vivências e discussões mais vivas e inclusivas.

\section{EDUCAÇÃO INCLUSIVA E ENSINO REGULAR}

A necessidade de uma aproximação dos professores, seja por meio de projetos relacionados à criação de materiais adaptados para o ensino, bem como à confecção destes para a utilização em sua prática docente, favorece a aprendizagem de todos os estudantes. Independentemente das disciplinas, é comum que um material adaptado favoreça a aprendizagem dos demais estudantes. Surge, então, a potência que uma prática diferenciada dos professores, na qual a sensibilidade para pensar 
na adequação de materiais e demais recursos nas salas de aula sirva de exemplo para ampliar a educação inclusiva para além do indicado na Política Nacional de Educação Especial na Perspectiva da Educação Inclusiva (2008), da LDB (1996) e do Decreto 7.611/2011, que dispõem sobre a criação de condições físicas, ambientais e materiais para o aluno, e seus encaminhamentos; bem como os protocolos internacionais que orientam as ações referentes ao respeito, educação e interação com as pessoas com deficiência, a exemplo da Convenção sobre os Direitos das Pessoas com Deficiência (2012), cujos protocolos orientam as ações no Brasil.

Rocha et al. (2015) também apresentam comparativos importantes em referência à aprendizagem de alunos surdos, com a utilização de recursos didáticos diferenciados, para o ensino da Biologia. Relatam acerca da importância de existir intérprete de libras em sala de aula, ampliar as experiências visuais e sensoriais, desenvolvendo e estimulando a criatividade e o interesse por assuntos da disciplina, dentre outros fatores. Enfatizam também que a motivação dos professores para elaborar aulas com metodologias inovadoras, que promovam conhecimentos científicos, beneficia não apenas os alunos surdos, mas também os demais alunos com necessidades educacionais especiais.

Ainda é possível verificar que, atualmente, conforme Fraga et al. (2017), a educação inclusiva deve abranger toda a comunidade escolar (professores, gestores, demais funcionários e familiares) com o objetivo de incluir os alunos com necessidades educacionais especiais no ensino regular, oferecendo-lhes uma educação de qualidade, assegurando a matrícula, permanência, participação e aprendizagem durante o processo de escolarização.

Batista e Manzoli (2016), por sua vez, abordam a necessidade de uma maior colaboração entre os profissionais da escola, e maior participação por parte da família, para que a educação inclusiva seja verdadeiramente realizada. Trazem também que o papel da educação especial seria o de disponibilizar instrumentos que ofereçam suporte e apoio para os estudantes com deficiência, para que o processo de inclusão possa, de fato, acontecer. 
Moreira (2015) discorre acerca da necessidade de formação inicial e continuada, entendendo que esta seria um disparador para repensar a inclusão escolar, no que diz respeito ao melhor preparo dos professores, para o enfrentamento da diversidade escolar e acadêmica. Nesse sentido, materializar-se-iam ações mais inclusivas e humanizadoras no contexto escolar.

Mediante esta vasta diversidade, é impossível o professor, sozinho, encontrar todas as respostas para os problemas que enfrenta no cotidiano escolar. Aponta-se a necessidade do professor buscar constantemente oportunidades para ampliar os seus conhecimentos, bem como outras possibilidades para superar as dificuldades que apareçam no decorrer do processo de inclusão.

A inclusão do aluno com necessidades educacionais especiais não deve se restringir à sua permanência em classe regular, ele necessita de mudanças que atendam às suas singularidades, para que possa aprender tudo o que sua potencialidade permitir. A escola precisa formar cidadãos críticos, inventivos e atuantes, indiferente de suas necessidades específicas. Para que ações educativas de qualidade se organizem, é necessário que sejam disponibilizados um ambiente adequado, investimento na estrutura, bem como formação dos profissionais, e estímulo à qualificação das práticas pedagógicas cotidianas (RESENDE; A.A.C.; LACERDA, C. B. F. de, 2013).

Estudos que visam analisar os aspectos da prática pedagógica desenvolvida por professores do Ensino Regular com alunos deficiência intelectual incluídos demonstram que há dificuldades cotidianas que refletem nas práticas pedagógicas desenvolvidas. Dentre as principais dificuldades para que a inclusão seja realizada, apontam: lacunas na formação docente, persistência de visão clínica da deficiência; pouca receptividade aos alunos com deficiência; inexistência de redes de apoio ao trabalho com tais discentes; pouca participação dos pais em todos os processos (SANTOS, T.C.C.; MARTINS, L.A.R., 2015).

A inclusão implica no envolvimento da pessoa com deficiências. Esse envolvimento precisa acontecer em todos os espaços que ela percorrer e desejar, seja na família, na rotina, na escola, nas atividades sociais ou. ainda, nas oportunidades 
que as comunidades têm a oferecer. Para que isso seja efetivado, é preciso colaboração dos agentes envolvidos: família, escola, professores, amigos e sociedade. Pimenta (1999, p. 23) aponta que "Educar na escola significa ao mesmo tempo preparar as crianças e os jovens para se elevarem ao nível da civilização atual - da sua riqueza e dos seus problemas - para aí atuarem".

\section{FORMAÇÃO DOCENTE E ENSINO REGULAR}

Entende-se a formação como processo permanente de desenvolvimento profissional, na perspectiva de que um olhar atento e qualificado do professor em sala de aula permite-lhe compreender as dificuldades dos alunos. Nesse sentido, considera-se a singularidade do aluno, oportunizando maior conhecimento frente às questões do ensino e aprendizagem.

A formação profissional para a educação inclusiva deve ser contínua, por meio de investimento na melhoria da qualidade de vida dos agentes envolvidos (professores, alunos e familiares), para que a escola seja vista como uma instituição que investe em educação integral e de qualidade (TRIÑANES; ARRUDA, 2014).

\section{CONSIDERAÇÕES FINAIS}

O estudo permitiu refletir sobre a atual conjuntura que a educação inclusiva repercute no sistema educacional de alunos com necessidades educacionais especiais no ensino regular. A partir das leituras, percebe-se a existência de uma aparente fragilidade na formação docente para atuar na educação inclusiva.

A falta de apoio da escola foi citação recorrente nestes estudos, bem como indicador marcante para fomentar a formação dos professores. O Ensino colaborativo também é significativamente citado como ferramenta potente para a qualificação do processo de formação continuada dos professores. Quando se cita "colaborativo" se faz jus a ações que permitam o ingresso, permanência e a formação qualificada desses alunos para viver em sociedade, por meio de ações em que os docentes possam ajudar-se mutuamente, na qualificação de seus fazeres. 
Então, exige-se que o professor que trabalha com alunos com necessidades educacionais especiais, ou não, tenha uma capacidade constante de refletir sobre suas práticas, para que, então, comece a aprender com seus erros e se reinvente diariamente. Nesse sentido, o desenvolvimento, tanto pessoal como profissional, fará parte do seu processo de formação, tornando-se uma estratégia eficaz para a melhoria da aprendizagem de pessoas com necessidades educacionais especiais.

Outro destaque é a questão da corresponsabilidade no processo formativo do aluno com necessidades educacionais especiais. Para tais mudanças acontecerem, a sociedade também deve ser responsabilizada, a partir da conscientização nos serviços públicos e privados, sobre as potencialidades das pessoas com algum tipo de necessidade educacional especial, para que se valorize a diversidade humana, buscando abolir os estereótipos em relação a estes estudantes, organizando a escola e as demais instituições sociais, da forma mais inclusiva possível, a partir das necessidades de cada indivíduo.

Desse modo, a pesquisa sistemática, baseada na análise de diversos artigos, permitiu compreender a temática que envolve a formação de professores, com foco na atuação desses profissionais na educação inclusiva, problematizando a necessidade de manutenção dos estudos sobre este assunto. A revisão sistemática possibilitou um levantamento bibliográfico do objeto de estudo, fomentando a reflexão acerca do quanto reinventar-se é necessário, visando a futuras produções nesta área de pesquisa.

Por fim, se vislumbra no contexto da educação inclusiva um cenário com potenciais melhorias em prol de uma educação de qualidade. Percebe-se que o aprendizado não é fácil de ser conquistado, e que nem todos aprendem da mesma forma e simultaneamente, uma vez que cada sujeito possui suas características, histórias de vida, dificuldades, potencialidades e formas de aprender.

\section{REFERÊNCIAS}

ARAÚJO, M. et al. Formação de professores e inclusão escolar de pessoas com deficiência: análise de resumos de artigos na base SciELO. Rev. Psicopedagogia, São Paulo, v. 27, n 84, 2010. Disponível em: 
$<$ http://www.revistapsicopedagogia.com.br/detalhes/195/formacao-de-professores-e-inclusao-escolar-de-pessoas-com-deficiencia--analise-de-resumos-de-artigos-na-base-scielo>. Acesso em: 31 jan. 2019.

ASPILICUETA, P. et al. A questão linguística na inclusão escolar de alunos surdos: ambiente regular inclusivo versus ambiente exclusivamente ouvinte. Revista Brasileira de Educação Especial, Marília, v. 19, n. 3, Jul/Set. 2013. Disponível em: <http://www.scielo.br/pdf/rbee/ v19n3/07.pdf>. Acesso em: 31 jan. 2019.

BATISTA, B. R.; MANZOLI, L. P. Educação Inclusiva: Um estudo de caso sobre o trabalho docente na educação infantil. Revista Ibero-Americana de Estudos em Educação, Araraquara, v. 11, n. esp. 2, 2016. Disponível em: <https://periodicos.fclar.unesp.br/ iberoamericana/article/download/8932/5874>. Acesso em: 31 jan. 2019.

BRANCHER, V. R. Trajetos E Representações De Docentes Da Pós-Graduação: Um Olhar a partir dos Imaginários e dos Dispositivos. 2013. Cap 5, f. 63-72.Tese (Doutorado em Programa de Pós-Graduação em Educação) - Universidade Federal de Santa Maria, Santa Maria, 2013.

BRASIL. Decreto $n^{0} 7.611$, de 17 de novembro de 2011. Dispõe sobre a educação especial, o atendimento educacional especializado e dá outras providências. Diário Oficial da União, DF, 18 nov. 2011.

BRASIL. Lei $n^{\circ}$ 9.394, de 20 de dezembro de 1996. Estabelece as diretrizes e bases da educação nacional. Diário Oficial da União, Brasília, DF, 23 dez. 1996.

BRASIL, Convenção sobre os Direitos das Pessoas com Deficiência (2007). Convenção sobre os Direitos das Pessoas com Deficiência: Protocolo Facultativo à Convenção sobre os Direitos das Pessoas com Deficiência: decreto legislativo $n^{\circ} 186$, de 09 de julho de 2008: decreto $n^{\circ}$ 6.949, de 25 de agosto de 2009. -- 4. ed., rev. e atual. - Brasília: Secretaria de Direitos Humanos, Secretaria Nacional de Promoção dos Direitos da Pessoa com Deficiência, 2011.

CABRAL, L. S. A. et al. Formação de professores e ensino colaborativo: proposta de aproximação. Rev. Ibero-Americana de Estudos em Educação, Araraquara, v. 9, n. 2, 2014. Disponível em: <https://periodicos.fclar.unesp.br/iberoamericana/article/view/7043/5056>. Acesso em: 31 jan. 2019.

DA ROSA, F. M. C.; BARALDI, I. M. O uso de narrativas (auto)biográficas como uma possibilidade de pesquisa da prática de professores acerca da Educação (Matemática) Inclusiva. Bolema, Rio Claro, v. 29, n. 53, Dez. 2015. Disponível em: <http://www.scielo.br/pdf/bolema/ v29n53/1980-4415-bolema-29-53-0936. pdf>. Acesso em: 31 jan. 2019.

DUEK, V. P. Formação continuada: análise dos recursos e estratégias de ensino para a educação inclusiva sob a ótica docente. Educação em Revista, Belo Horizonte, v. 30, n. 2, Abr/ Jun. 2014. Disponível em: <http://www.scielo.br/pdf/edur/v30n2/02.pdf> Acesso em: 31 jan. 2019.

FERNANDES, T. L. G.; VIANA, T. V. Alunos com necessidades educacionais especiais (NEEs): avaliar para o desenvolvimento pleno de suas capacidades. Estudos em Avaliação Educacional, São Paulo, v. 20, n. 43, 2009. Disponível em: <http://www.fcc.org.br/pesquisa/ publicacoes/eae/arquivos/1495/1495.pdf>. Acesso em: 31 jan. 2019. 
FRAGA, J. M. et al. Conceitos e relações entre educação inclusiva e educação especial nas legislações educacionais do Brasil, Santa Catarina e Blumenau. Revista Educação Especial, Santa Maria, v. 30, n. 57, Jan/Abr. 2017. Disponível em: <https://periodicos.ufsm.br/educacaoespecial/article/view/22012>. Acesso em: 31 jan. 2019.

GALVÃO, T. F.; PEREIRA, M. G. Revisões sistemáticas da literatura: passos para sua elaboração. Epidemiol Serv Saúde, Brasília, vol. 21, n. 1, Jan/Mar. Disponível em: <http://scielo.iec.gov.br/pdf/ess/v23n1/v23n1a18.pdf>. DOI: 10.5123/S1679-49742014000100018. Acesso em: 31 jan. 2019.

GLAT, R.; PLETSCH, M. D. O papel da Universidade no contexto da política de Educação Inclusiva: reflexões sobre a formação de recursos humanos e a produção de conhecimento. Revista de Educação Especial, Santa Maria, v. 23, n. 38, Set/Dez. 2010. Disponível em: <hppt://www.ufsm.br/revistaeducacaoespecial>. Acesso em: 07 jul. 2018.

LIMA-RODRIGUES, L. M. S. Formação ativa e expressiva de professores: "bagunçando o coreto" para estimular a inclusão. Revista Educação Especial, Santa Maria, v. 30, n. 59, Set/Dez. 2017. Disponível em: <https://periodicos.ufsm.br/educacaoespecial/article/view/ 28428>. Acesso em: 31 jan. 2019.

LOPES, C. Artes Visuais: um contributo para a inclusão de alunos com dificuldades de aprendizagem (um estudo de caso). 2010. Dissertação (Mestrado) - Universidade Lusófona de Humanidades e Tecnologias, Lisboa, 2010.

MACHADO, C. F.; COSTAS, F. A. T. O papel da gestão na formação inicial de professores com vistas à educação inclusiva. Regae: Rev. Gest. Aval. Educ. Santa Maria, v. 2 n. 3, Jan./ Jun. 2013 p. 73-92. Disponível em: <https://periodicos.ufsm.br/regae/article/viewFile/10500/ pdf>. Acesso em: 30 jan. 2019.

MAGALHÃES, R. C. B. (Org.). Reflexões sobre a diferença: uma introdução à educação especial. Fortaleza: Demócrito Rocha, 2003.

MATOS, S. N.; MENDES, E. G. Demandas de professores decorrentes da inclusão escolar. Revista Brasileira de Educação Especial, Marília, v. 21, n. 1, Jan/Mar. 2015. Disponível em: < http://www.scielo.br/pdf/rbee/v21n1/1413-6538-rbee-21-01-00009.pdf>. Acesso em: 31 jan. 2019.

MOREIRA, G. E. A Educação matemática inclusiva no contexto da pátria educadora e do novo PNE: reflexões no âmbito do GD7. Educ. Matem. Pesq., São Paulo, v.17, n. 3, 2015. Disponível em: <https://revistas.pucsp.br/emp/article/view/25667/pdf>. Acesso em: 31 jan. 2019.

OTALARA, A. P; DALL'ACQUA,M. J. C. Formação de professores para alunos público-alvo da educação especial: algumas considerações sobre limites e perspectivas. Revista IberoAmericana de Estudos em Educação, Araraquara, v. 11, n. esp. 2, p.1048-1058, 2016. Disponível em: <https://periodicos.fclar.unesp.br/iberoamericana/article/viewFile/8943/5886>. Acesso em: 31 jan. 2019.

PIMENTA, S. G. Formação de professores: identidade e saberes da docência. In: PIMENTA, S. G. (Org). Saberes pedagógicos e atividade docente. São Paulo: Cortez Editora, 1999. p. $15-34$. 
PLETSCH, M. D.; ARAÚJO, D. F.; LIMA, M. F. C. Experiências de formação continuada de professores: possibilidades para efetivar a inclusão escolar de alunos com deficiência intelectual. Periferia, educação,cultura e comunicação, Rio de Janeiro, v.9, n.1, Jan/Jun. 2017. Disponível em: <https://www.e-publicacoes.uerj.br/index.php/periferia/article/view/ 29187/20729>. Acesso em: 31 jan. 2019.

REGIANI, A. M.; MÓL, G. S. Inclusão de uma aluna cega em um curso de licenciatura em Química. Ciência \& Educação, Brasília, v. 19, n. 1, 2013. Disponível em: < http://www.scielo.br/pdf/ciedu/v19n1/09.pdf>. Acesso em: 31 jan. 2019.

RESENDE, A. A. C.; LACERDA, C. B. F. Mapeamento de alunos surdos matriculados na rede de ensino pública de um município de médio porte do Estado de São Paulo: dissonâncias. Revista Brasileira de Educação Especial, Marília, v. 19, n. 3, 2013. Disponível em: <http://www.scielo.br/pdf/rbee/v19n3/08.pdf> Acesso em: 31 jan. 2019.

ROCHA, L. R. M et al. Educação de surdos: relato de uma experiência inclusiva para o ensino de ciências e biologia. Revista Educação Especial, Santa Maria, v. 28, n. 52, Maio/Ago 2015. Disponível em: <https://www.researchgate.net/publication/277352620_Educacao_de_surdos_relato_de_uma_experiencia_inclusiva_para_o_ensino_de_ciencias_e_biologiar. Acesso em: 31 jan. 2019.

RODRIGUES, D.; LIMA-RODRIGUES, L. Educação Física: formação de professores e inclusão. Práxis Educativa, Ponta Grossa, v. 12, n. 2, Maio/Ago. 2017. Disponível em: <http:// www.revistas2.uepg.br/index.php/praxiseducativa/article/view/9812/5688>. Acesso em: 31 jan. 2019.

SANTOS, T. C. C.; MARTINS, L. de A. R. Práticas de professores frente ao aluno com deficiência intelectual em classe regular. Revista Brasileira de Educação Especial, Marília, v. 21, n. 3, 2015. Disponível em: <http://www.scielo.br/pdf/rbee/v21n3/1413-6538rbee-21-03-00395.pdf>. Acesso em: 31. jan. 2019.

SANTOS, A. F.; ARAÚJO, R. N. A formação de professores para a prática inclusiva: um olhar crítico. Revista Interfaces da Educ., Paranaíba, v.7, n.19, 2016. Disponível em: <http://periodicosonline.uems.br/index.php/interfaces/article/view/764/955>. Acesso em: 10 fev. 2019.

SASSAKI, R. K. Inclusão: o paradigma do século 21. Revista da Educação Especial, Marília, Out. 2005. Disponível em: <http://portal.mec.gov.br/seesp/arquivos/pdf/revistainclusao1.pdf>. Acesso em: 31. Jan. 2019.

SILVA, L. C. Formação de professores: desafios à educação inclusiva. Revista Ibero-Americana de Estudos em Educação, Araraquara, v.10, n. esp. 2015. Disponível em: <https:// periodicos.fclar.unesp.br/iberoamericana/article/view/7920>. Acesso em: 30 jan. 2019.

SILVA, M. O. E. Dados de Investigação em Ciências da Educação e em Artes Visuais: testemunho para a construção da Escola Inclusiva. Revista Lusófona de Educação, Lisboa, n. 25, 2013. Disponível em: <revistas.ulusofona.pt/index.php/rleducacao/article/view/ 4386/2977>. Acesso em: 31 jan. 2019.

PRAIS, J. L.S.; DA ROSA, V. F. A Formação de professores para inclusão tratada na Revista Brasileira de Educação Especial: uma análise. Revista Brasileira Educação Especial, Brasília, v. 30, n. 57, 2017. Disponível em:<https://periodicos.ufsm.br/educacaoespecial/article/view/19833/pdf>. Acesso em: 31 jan. 2019. 
TAVARES, L. M. F. L.; SANTOS, L. M. M.; FREITAS, M. N. C. A Educação Inclusiva: Um estudo sobre a formação docente. Revista Brasileira de Educação Especial, Marília, v. 22, n. 4, 2016. Disponível em: <http://www.scielo.br/pdf/rbee/v22n4/1413-6538rbee-22-04-0527.pdf>. Acesso em: 31 jan. 2019.

THESING, M. L. C.; COSTAS, F. A. T. A. Epistemologia na Formação de Professores de Educação Especial: Ensaio sobre a Formação Docente. Rev. Bras. Ed. Esp., Marília, v. 23, n.2, Abr/Jun. 2017. Disponível em: <https://www.researchgate.net/publication/ 318278270_A_Epistemologia_na_Formacao_de_Professores_de_Educacao_Especial_Ensaio_sobre_a_Formacao_Docente>. Acesso em: $\overline{3} 1$ jan. 2019.

TRIÑANES, M. T. R.; ARRUDA, S. M. C. P. Atividades de vida autônoma na escola de tempo integral: aluno com deficiência visual-perspectivas educacionais. Revista Brasileira de Educação Especial, Marília, v. 20, n. 4, 2014. Disponível em: <http://www.scielo.br/pdf/rbee/ v20n4/a09v20n4.pdf>. Acesso em: 31 jan. 2019.

VITALIANO, C. R. (Org.). Formação de professores para inclusão de alunos com necessidades educacionais especiais. Londrina: EDUEL, 2010.

ZABALZA, Miguel. 0 ensino universitário: seu cenário e seus protagonistas. Porto Alegre: Artmed, 2004.

Recebido em 22 de julho de 2018 Aprovado em 25 de setembro de 2019 